\title{
Mastitis prevention and control practices and mastitis treatment strategies associated with the consumption of (critically important) antimicrobials on dairy herds in Flanders, Belgium
}

\author{
M. Stevens, ${ }^{1}$ S. Piepers, and S. De Vliegher \\ M-team and Mastitis and Milk Quality Research Unit, Department of Reproduction, Obstetrics and Herd Health, Faculty of Veterinary Medicine, \\ Ghent University, 9820 Merelbeke, Belgium
}

\begin{abstract}
The main objectives of this study were to evaluate to what extent variations in herd-level antimicrobial consumption (AMC) can be explained by differences in management practices that are consistently effective in the prevention of (sub)clinical mastitis, on the one hand, and by differences in mastitis treatment strategies, on the other hand. Antimicrobial consumption data were obtained during 2012 and 2013 by "garbage can audits" and expressed as antimicrobial treatment incidences (ATI) for all compounds combined (total ATI) and for the critically important antimicrobials for human health separately. Data on mastitis prevention and control practices were obtained via face-to-face interviews performed during herd visits in March 2013. Some management practices and treatment strategies related to udder health were associated with the total AMC. However, the results demonstrated that implementing effective udder health management practices does not necessarily imply a low AMC and vice versa. Herds participating in a veterinary herd health management program and herds selectively drying off cows used fewer antimicrobials compared with herds not participating in such a program or applying blanket dry-cow therapy. Moreover, herds treating (some) (sub)clinical mastitis cases with intramammary homeopathic substances consumed fewer antimicrobials than herds not applying such homeopathic treatments. Besides these factors, no other direct association was found between effective udder health management practices on the one hand and AMC on the other hand. Also, the use of critically important antimicrobials was only associated with the way in which subclinical mastitis cases were treated. The latter indicates that the AMC of criti-
\end{abstract}

Received October 7, 2015.

Accepted December 28, 2015.

${ }^{1}$ Corresponding author: Marina.Stevens@Ugent.be cally important antimicrobials is potentially driven by factors other than those included in this study such as those related to the "mindset" of the veterinarians and their farmers. Future research should therefore aim to unravel the reasoning of vets and their farmers behind the use of those critically important antimicrobials for the treatment of mastitis and other diseases.

Key words: antimicrobial treatment incidence, mastitis prevention and control practice, mastitis treatment strategy

\section{INTRODUCTION}

Most antimicrobials are used for the prevention and control of mastitis in dairy herds (Mitchell et al., 1998; Pol and Ruegg, 2007; Menéndez González et al., 2010; Ivemeyer et al., 2012). In addition, antimicrobial consumption (AMC) is associated with both the dry-cow strategy (blanket versus selective) and the incidence rate of treated mastitis (IRTM; positive association; Stevens et al., 2016).

Mastitis remains a major issue in dairy production, despite the fact that prevention and control programs have been available since the 1960s and have been successfully implemented on many herds (Hillerton et al., 1995). Over the years, a large number of studies has focused on the identification of management risk factors for both clinical (CM; Barkema et al., 1999a,b; Huijps et al., 2010; Gordon et al., 2013; Richert et al., 2013) and subclinical mastitis (SCM; Barkema et al., 1999b; Huijps et al., 2010; Dufour et al., 2011, 2012; Piepers et al., 2011; Gordon et al., 2013). Postmilking teat disinfection, blanket dry-cow therapy, keeping cows standing following milking, the use of milkers' gloves, and back-flushing the milk cluster after milking a cow with (sub)clinical mastitis or milking them last have been identified as the most effective preventive measures for lowering the incidence of either CM or SCM (Hogeveen et al., 2011; Dufour et al., 2012; Lees and Lievaart, 2013). Given that the IRTM is strongly associated with total AMC on dairy herds (Lago et al., 2014; Stevens 
et al., 2016), we can anticipate that (some of) these specific mastitis prevention and control practices are related to AMC. In addition, factors related to mastitis treatment strategies in a herd might hypothetically be associated with AMC in general, and with consumption of the critically important antimicrobials for human health in particular.

The main objective of this study was to evaluate to what extent variations in total antimicrobial treatment incidences (ATI) and ATI of critically important antimicrobials can be explained by differences in management practices that have been identified as the most effective for lowering the incidence of mastitis, on the one hand, and by differences in mastitis treatment strategy, on the other hand.

\section{MATERIALS AND METHODS}

\section{Data Collection}

Initial Data Set and Data Handling. The data used in this study are described elsewhere (Stevens et al., 2016). In brief, the data originated from a convenience sample of 57 Flemish dairy herds participating in the Flemish DHI program, with an interval of 4 to 6 wk between 2 test-days, and were collected during 2012 and 2013. Antimicrobial consumption data were retrieved by "garbage can audits." The garbage cans were 51-L receptacles with an open top. Farmers were asked to collect all empty drug vials and tubes used to treat adult dairy cattle (i.e., from the first calving). The garbage cans were positioned at the most convenient spot (e.g., near the drug storage area or in the milking parlor) and were collected twice (August 31, 2012, and February 28, 2013) for processing by the first author. Product name, volume, and number of receptacles were registered using a datasheet that included herd identification number and starting and end date of collection for that particular herd. The AMC at herd level was quantified by the antimicrobial treatment incidence (ATI). Therefore, the total amount of active substances used during the study period was divided by the defined daily dose animal (DDDA) multiplied by the herd-level cow-days. The total amount of active substances was calculated by multiplying the volume per receptacle by the total number of used receptacles and by the concentration of the drug. The ATI was defined as the number of DDDA used per 1,000 cows per day.

Mastitis Prevention and Control Practices. Data on mastitis prevention and control practices were obtained using a large questionnaire (available on request) administered through a face-to-face interview with each farmer during a herd visit in March 2013. The questionnaire took approximately 60 to $90 \mathrm{~min}$ to complete. The questions included general information and information related to the milking technique, the milking machine, the accommodation of lactating cows, treatment strategies of cases of $\mathrm{CM}$ and SCM, the dry-cow management, culling of cows, heifer management and treatment, general herd health status, and participation in a veterinary herd health management (VHHM) program. All questions referred to practices in place during the AMC quantification period (i.e., 2012-2013). The questionnaire was pretested and finetuned in close cooperation with several dairy farmers before the start of the study. Eventually, only the questions related to management practices $(\mathrm{n}=9)$ that have been shown to be consistently effective in the prevention of (sub)clinical mastitis (Huijps et al., 2010; Hogeveen et al., 2011; Lees and Lievaart, 2013) were included for further analyses. These questions were further complemented with information capturing treatment strategies of $\mathrm{CM}$ and SCM cases (5 questions).

\section{Statistical Analyses}

First, the relationship between individual categorical variables ["use of a separate cloth to clean the udder"; "wearing milker's gloves during milking"; "application of postmilking teat disinfection"; "rinsing of milking cluster after milking a cow with (sub)clinical mastitis or milking these cases last"; "keeping cows standing after milking"; "replacement of teat cup liners"; "drycow strategy"; "dry-cow minerals provided"; "VHHM program"; "route of administration for treatment CM"; "treatment duration CM"; "route of administration for treatment SCM"; "treatment duration of SCM"; "use of intramammary homeopathic substances for treatment of CM or SCM"] and the continuous outcome variables total ATI and ATI of critically important antimicrobials [i.e., third- and fourth-generation cephalosporins and fluoroquinolones according to the World Organization for Animal Health (Office International des Épizooties)] was examined using simple linear regression models (SPSS statistics 22.0, IBM Corp., New York, NY). Only independent variables associated at a significance level $P \leq 0.20$ were considered for further analyses. Pearson and Spearman rank correlation coefficients were calculated among the significant independent variables to avoid multicollinearity in the next steps. If 2 management practices had a correlation coefficient $\geq|0.6|$, only the one with the highest statistical significance was selected for further analysis.

Second, the association between factors that were significantly associated in the abovementioned univari- 
able models at a significance level of $P \leq 0.20$ and that were not highly correlated with each other, and the continuous outcome variables total ATI and ATI of the critically important antimicrobials was examined with multivariable linear regression analysis (SPSS statistics 22.0, IBM Corp.). The model always included an independent categorical variable capturing whether a farmer indicated that products also used in young stock or by the veterinarian were collected in the garbage can $(1=$ only antimicrobials used by the famer in adult cattle collected; 2 = antimicrobials used in young stock or by veterinarians also collected) as previous results suggest that this variable could act as a confounder (Stevens et al., 2016). The latter variable was forced in the model. Because this variable was not available for 1 herd, the multivariable analyses included only 56 herds. Other nonsignificant variables were considered to act as confounders if their removal made the regression coefficients of the remaining variables undergo a relative change of $>25 \%$ or, in case the regression coefficient ranged between -0.4 and 0.4 , if an absolute change $>0.1$ was observed (Noordhuizen, 2001). Nonsignificant variables were removed using backward elimination at $P \leq 0.05$. The adequacy of the final model was tested by examining normal probability plots of residuals and plots of residuals versus predicted values to check whether the assumptions of normality and homogeneity of variance had been fulfilled. No patterns indicating heteroscedasticity were revealed. Results are described as back-transformed least squares means.

\section{RESULTS}

\section{Descriptive Results}

The average total ATI was 20.78 DDDA per 1,000 cow-days (Stevens et al., 2016). The average ATI of the critically important antimicrobials for human health was 8.59 DDDA. All herds except 1 used critically important antimicrobials. Large between-herd variation existed both in the total ATI as well as in the ATI of critically important antimicrobials.

\section{Univariable Associations}

A first reduction based on univariable associations revealed that 3 and 1 mastitis prevention and control practices and 4 and 2 mastitis treatment strategies were associated with total ATI and ATI of the critically important antimicrobials, respectively (Table 1 ). Timely replacement of teat cup liners, blanket dry-cow strategy, no participation in a VHHM program, treatment duration of $\mathrm{CM}$ for $\geq 3 \mathrm{~d}$, intramammary and systemically treatment of SCM, treatment duration of

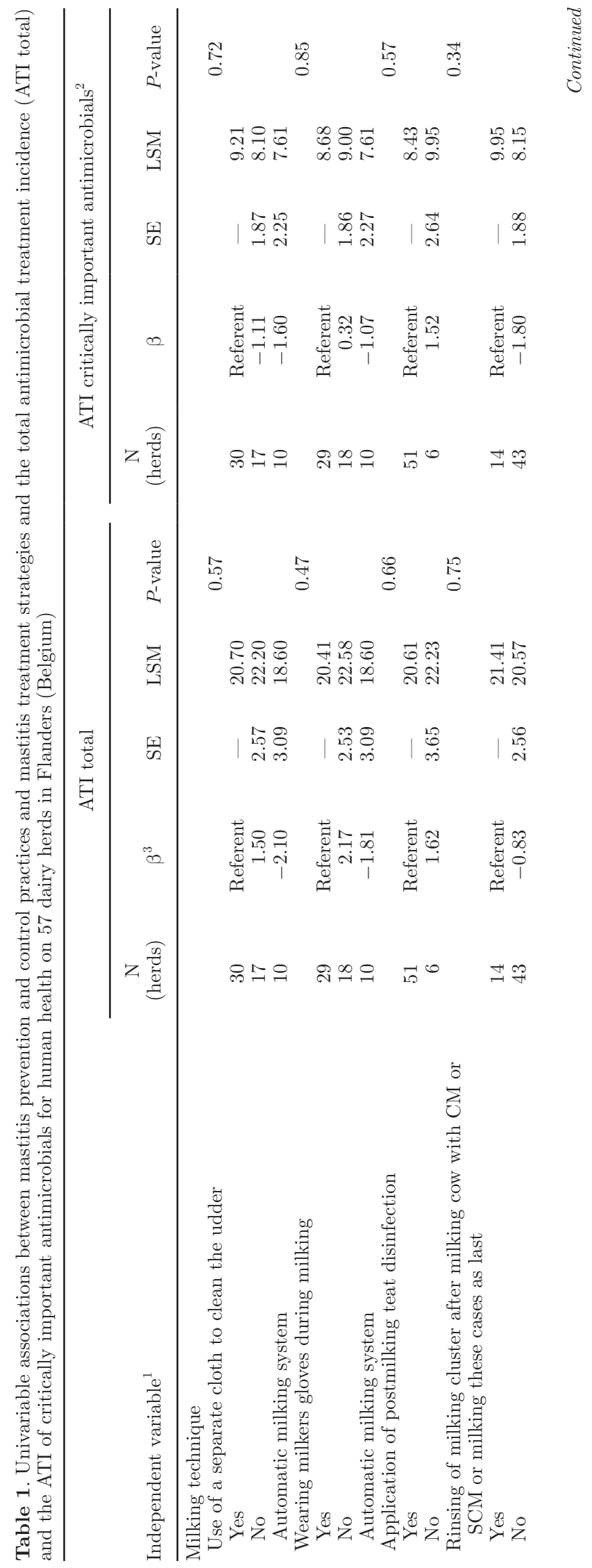


MASTITIS PREVENTION, CONTROL, AND TREATMENT PRACTICES

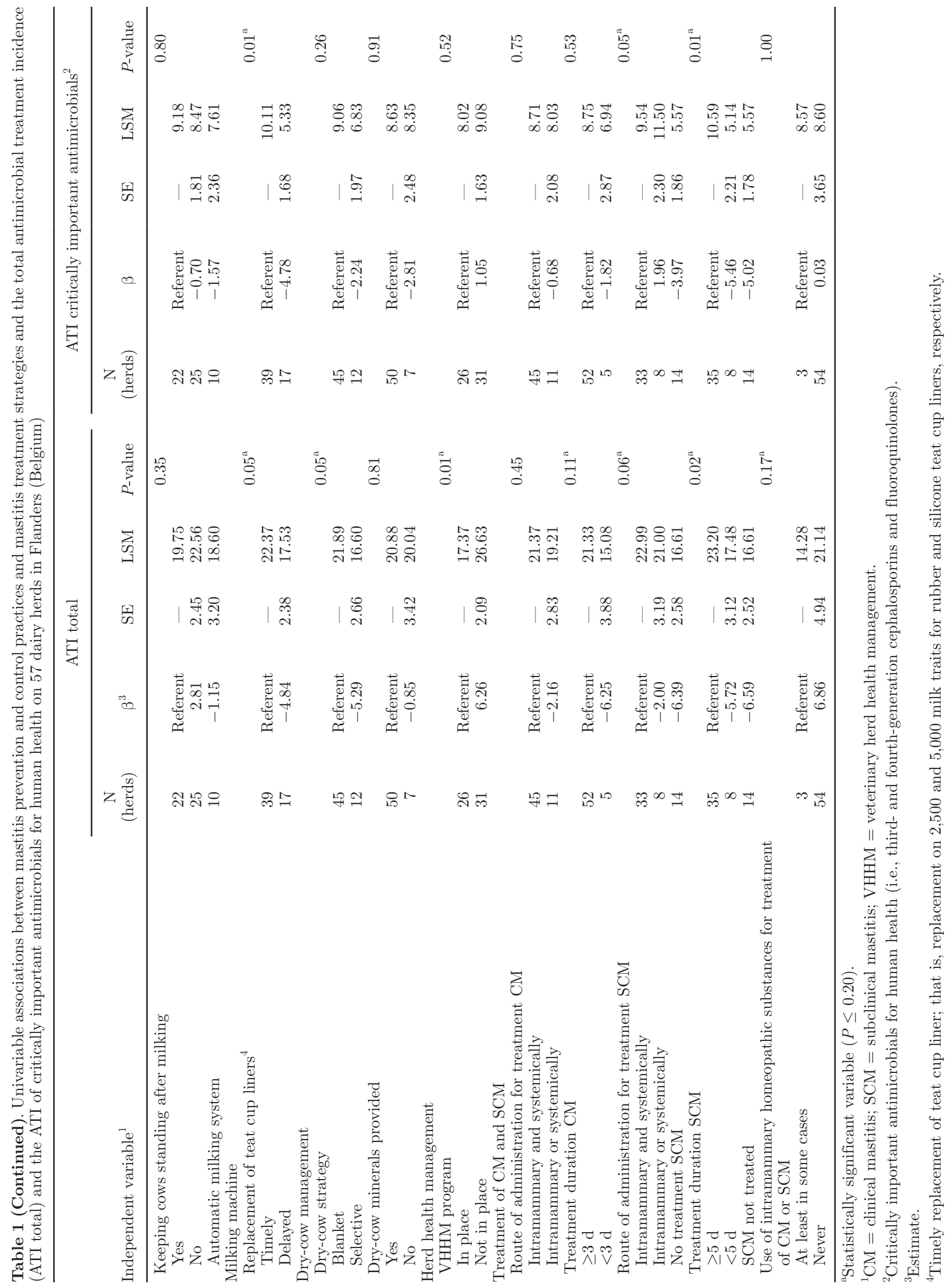


Table 2. Final multivariable model describing the relation between mastitis prevention and control practices and mastitis treatment strategies with the total antimicrobial treatment incidence (ATI) on 56 dairy farms in Flanders (Belgium) ${ }^{1}$

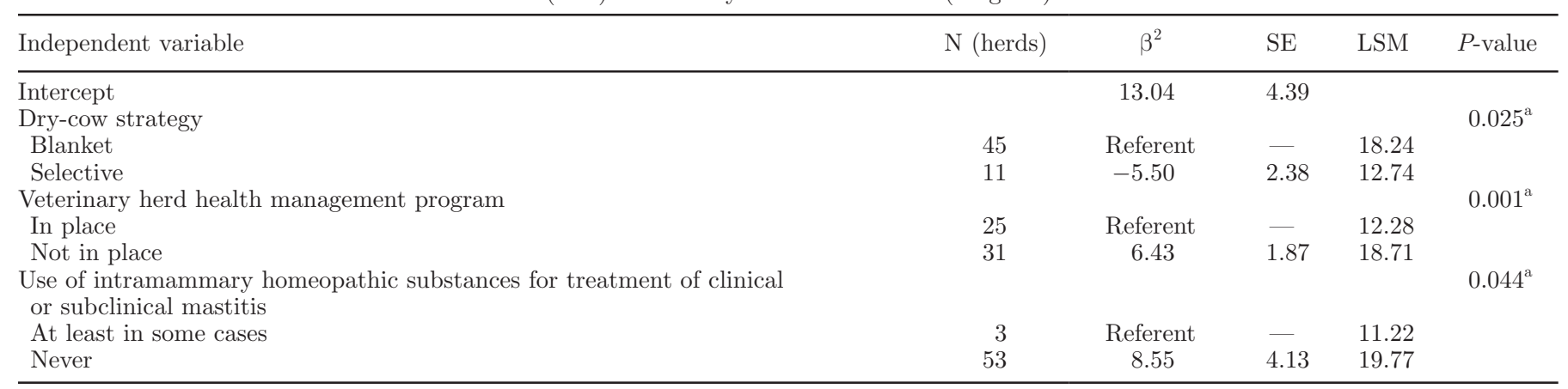

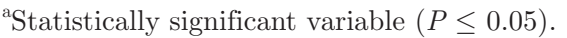

${ }^{1}$ Taking into account an independent categorical variable capturing whether a farmer indicated that products also used in young stock or by the veterinarian were collected in the garbage can $(1=$ only antimicrobials used in adult cattle collected; $2=$ antimicrobials used in young stock or by veterinarians also collected).

${ }^{2}$ Estimate.

$\mathrm{SCM}$ for $\geq 5 \mathrm{~d}$, and no use of intramammary homeopathic substances for the treatment of $\mathrm{CM}$ or SCM were significantly associated with a high total ATI at a significance level of $P \leq 0.20$. Timely replacement of teat cup liners, intramammary and systemically treatment of SCM, and treatment duration of SCM for $\geq 5$ d were significantly associated at $P \leq 0.20$ with a high ATI of critically important antimicrobials. A strong correlation $(\mathrm{r}=0.605)$ was found between the administration route of antimicrobials for the treatment of SCM and treatment duration of SCM. Treatment duration of SCM showed the highest statistical significance and was therefore selected for further analysis.

\section{Final Multivariable Model}

The total ATI was lower on herds where selective dry-cow therapy was applied, where a VHHM program was in place, and where at least some of the (sub)clinical mastitis cases were intramammary treated with a homeopathic substance compared with herds where blanket dry-cow therapy was applied, a VHHM program was not in place, and mastitis cases were not treated intramammary with homeopathic substances $(P \leq 0.05$; Table 2$)$. The ATI of critically important antimicrobials was higher on herds that treated SCM $\geq 5 \mathrm{~d}$ compared with herds that did not treat SCM or that treated $\mathrm{SCM} \leq 5 \mathrm{~d}(P \leq 0.05)$.

\section{DISCUSSION}

This is the first study to focus on the identification of mastitis prevention and control practices and mastitis treatment strategies associated with ATI on dairy herds and the use of critically important antimicrobials for human health in particular. The AMC was determined via garbage can audits, the advantages and disadvantages of which have been recently discussed by Stevens et al. (2016). In the latter study, we demonstrated that the variation in ATI between dairy herds was partly explained by differences in the IRTM and in dry-cow strategy (Stevens et al., 2016). Therefore, we hypothesized that established mastitis prevention and control strategies could explain at least some of the variation in the ATI. Remarkably, only a few of these practices and mastitis treatment strategies were associated with the total ATI and with the ATI of critically important antimicrobials on Flemish dairy herds.

Some preventive udder health management practices, as well as mastitis treatment strategies, were significantly associated with ATI. Still, this does not prove causality. Moreover, factors influencing management practices or applied mastitis treatment strategies on the one hand and ATI on the other hand could act as confounders. Delayed replacement of teat cup liners was associated with a lower total ATI in the univariable analysis. However, this association disappeared in the multivariable model due to confounding by the treatment duration of SCM. The close relationship between treating SCM cases (i.e., a crucial step in obtaining and maintaining a good udder health; Barkema et al., 2013), timely replacement of teat liners (i.e., an effective udder health management practice; Huijps et al., 2010), and a high ATI substantiates the complexity of how dairy cows are managed and how producers make decisions. It also cautions against oversimplifying the debate on how a reduced and more responsible use of antimicrobials should be reached. Our results demon- 
strate at least that implementing effective udder health management practices does not necessarily imply a low AMC and vice versa. An alternative explanation might be that, in some situations, the approach to mastitis control is haphazard, with farmers focusing on specific areas thought to be responsible for causing the problem. Farmers struggling with udder health problems might start changing their milking routine (i.e., wearing gloves, use of a separate cloth, rinsing the milking cluster after a high risk cow was milked, and so on) as those factors are generally considered to be very effective, whereas the real problem arises from the milking machine functioning, poor environmental conditions, or the dry period. Additionally, implementing good udder health management does not necessarily protect a dairy herd from other diseases such as fertility problems, respiratory disorders, and claw diseases. The majority of antimicrobials were used for intramammary use, although more than one-third was administered systemically, of which likely only a part would have been applied for the treatment of mastitis (Stevens et al., 2016). Unfortunately, no detailed information was available on the indications for which the systemically administered drugs were specifically applied.

The total ATI on herds that practiced selective drycow therapy was lower compared with herds implementing blanket dry-cow therapy, which is in agreement with the findings of Scherpenzeel et al. (2014). The relative number of herds that applied blanket dry-cow therapy in this study (79.0\%) approached the $81.4 \%$ obtained in a recently conducted Flemish survey (K. Supré, Flemish Milk Control Center, Belgium, personal communication) and the $73.5 \%$ across different studies in the United States. It was somewhat lower compared with the 87 and $88 \%$ in the Netherlands and Canada, respectively (Pol and Ruegg, 2007; Sampimon et al., 2008; Barlow, 2011; Dufour et al., 2012). The success of selective dry-cow treatment with respect to udder health in the next lactation depends on several factors such as the applied cow-level selection criteria and the infection pressure to which the cows are exposed during the dry period. In the present study, the criteria applied to decide on selective rather than blanket dry-cow treatment varied widely among herds. Also, no detailed information was available on the hygienic conditions during the dry period nor on the cows' udder health status after calving. Although selective dry-cow therapy might result in an increased incidence rate of CM and SCM in the next lactation under some circumstances, the average reduction in AMC by drying-off cows selectively will apparently not be compensated by the increase in AMC for treating $\mathrm{CM}$ in the next lactation (Scherpenzeel et al., 2014).
Herds participating in a VHHM program used fewer antimicrobials, which is in accordance with the findings of Ivemeyer et al. (2012). About half of the producers indicated they participate in some sort of VHHM program, which is low compared with the numbers reported in the Netherlands (Derks et al., 2013). In most herds in our study, the VHMM program consisted primarily of regular fertility checks only. In a minority of herds, the regular fertility checks were combined with udder health monitoring, and a follow-up of nutrition, young stock rearing, and claw health. Participation in a VHHM program is associated with a lower AMC, which indicates a positive interaction between producers and veterinarians and an increased awareness among farmers of AMC-related potential risks. Producers who strive for optimal management might also be more aware of the benefits of participating in a VHHM program. Strikingly, the use of critically important antimicrobials was not related to participation in such program.

The use of homeopathic drugs for intramammary treatment of CM and SCM cases was associated with a lower total ATI. However, only a minority of the producers indicated the use of intramammary homeopathic remedies as part of their mastitis treatment strategy. Homeopathic treatment of CM cases resulted in lower clinical and bacteriological cure rates compared with antimicrobial treatment in one study (Williamson and Lacy-Hulbert, 2014) but not in others (Hektoen et al., 2004; Werner et al., 2010). Intramammary infections might (spontaneously) cure, although the cure rate strongly depends on the pathogen involved. Further research is needed to reveal to what extent the potentially increased use of antimicrobials related to the higher incidence of recurrent mastitis cases outweighs the decrease in AMC by not treating all mastitis cases with antimicrobials.

The strong positive association between the treatment duration of SCM and ATI of critically important antimicrobials suggests that extended treatment of SCM is typically performed using the latter products. If the latter association is real and thus not confounded by other factors, these treatment decisions can be heavily criticized. Third- and fourth-generation cephalosporins and fluoroquinolones (i.e., the critically important antimicrobials) are so-called broad-spectrum antimicrobials, and most SCM cases were caused by grampositive bacteria (data not shown). Still, no detailed information is available on the indications for which the different systemically administered antimicrobials were specifically used or on the herd-level prevalence of diseases other than mastitis. Therefore, caution is needed in drawing conclusions. Interestingly, no other 
management practices or treatment strategies were associated with the use of critically important antimicrobials, which indicates that the AMC of critically important antimicrobials is potentially driven by factors other than those included in this study. Those factors might be related to the market availability of certain products, the influence of the social environment (i.e., positive references, awareness of what others say or do), the strength of marketing strategies of the pharmaceutical companies, previous experience, or differences in withdrawal time between products.

\section{CONCLUSIONS}

We identified mastitis prevention and control practices and treatment strategies associated with the consumption of antimicrobials on Flemish dairy herds. Only limited management practices and treatment strategies were associated with total ATI and ATI of critically important antimicrobials, which indicates that $\mathrm{AMC}$ is potentially driven by factors other than the ones included in this study. Herds participating in a VHHM program and herds selectively drying off cows used fewer antimicrobials than herds not participating in such a program or applying blanket dry-cow therapy. Moreover, herds treating (some) (sub)clinical mastitis cases intramammary with homeopathic substances consumed fewer antimicrobials than herds not using such homeopathic treatments. Future research should aim at determining the reasoning of vets and their farmers behind the use of specific classes of antimicrobial drugs for the treatment of mastitis and other diseases.

\section{ACKNOWLEDGMENTS}

All farmers who cooperated are gratefully acknowledged. Special word of thanks to all M-team (UGent) colleagues for helping with the herd visits. Thanks must go to the Milk Control Centre Flanders (Lier, Belgium), the Farmers Union (Boerenbond, Leuven, Belgium), the Milk Quality Label (IKM-QFL, Brussels, Belgium), and the Belgian Confederation of the Dairy Industry (BCZ, Leuven, Belgium) for partially financing this study.

\section{REFERENCES}

Barkema, H. W., S. De Vliegher, S. Piepers, and R. N. Zadoks. 2013. Herd level approach to high bulk milk somatic cell count problems in dairy cattle. Vet. Q. 33:82-93.

Barkema, H. W., Y. H. Schukken, T. Lam, M. L. Beiboer, G. Benedictus, and A. Brand. 1999a. Management practices associated with the incidence rate of clinical mastitis. J. Dairy Sci. 82:1643-1654.
Barkema, H. W., J. D. Van der Ploeg, Y. H. Schukken, T. Lam, G. Benedictus, and A. Brands. 1999b. Management style and its association with bulk milk somatic cell count and incidence rate of clinical mastitis. J. Dairy Sci. 82:1655-1663.

Barlow, J. 2011. Mastitis therapy and antimicrobial susceptibility: A multispecies review with a focus on antibiotic treatment of mastitis in dairy cattle. J. Mammary Gland Biol. Neoplasia 16:383-407.

Derks, M., T. van Werven, H. Hogeveen, and W. D. J. Kremer. 2013. Veterinary herd health management programs on dairy farms in the Netherlands: Use, execution, and relations to farmer characteristics. J. Dairy Sci. 96:1623-1637.

Dufour, S., I. R. Dohoo, H. W. Barkema, L. DesCoteaux, T. J. DeVries, K. K. Reyher, J. P. Roy, and D. T. Scholl. 2012. Manageable risk factors associated with the lactational incidence, elimination, and prevalence of Staphylococcus aureus intramammary infections in dairy cows. J. Dairy Sci. 95:1283-1300.

Dufour, S., A. Frechette, H. W. Barkema, A. Mussell, and D. T. Soholl. 2011. Invited review: Effect of udder health management practices on herd somatic cell count. J. Dairy Sci. 94:563-579.

Gordon, P. F., B. H. P. van den Borne, M. Reist, S. Kohler, and M. G. Doherr. 2013. Questionnaire-based study to assess the association between management practices and mastitis within tie-stall and free-stall dairy housing systems in Switzerland. BMC Vet. Res. 9:200.

Hektoen, L., S. Larsen, S. A. Odegaard, and T. Loken. 2004. Comparison of homeopathy, placebo and antibiotic treatment of clinical mastitis in dairy cows-Methodological issues and results from a randomized-clinical trial. J. Vet. Med. A Physiol. Pathol. Clin. Med. 51:439-446.

Hillerton, J. E., A. J. Bramley, R. T. Staker, and C. H. McKinnon. 1995. Patterns of intramammary infection and clinical mastitis over a 5-year period in a closely monitored herd applying mastitis control measures. J. Dairy Res. 62:39-50.

Hogeveen, H., K. Huijps, and T. Lam. 2011. Economic aspects of mastitis: New developments. N. Z. Vet. J. 59:16-23.

Huijps, K., H. Hogeveen, T. Lam, and A. Lansink. 2010. Costs and efficacy of management measures to improve udder health on Dutch dairy farms. J. Dairy Sci. 93:115-124.

Ivemeyer, S., G. Smolders, J. Brinkmann, E. Gratzer, B. Hansen, B. I. F. Henriksen, J. Huber, C. Leeb, S. March, C. Mejdell, P. Nicholas, S. Roderick, E. Stoeger, M. Vaarst, L. K. Whistance, C. Winckler, and M. Walkenhorst. 2012. Impact of animal health and welfare planning on medicine use, herd health and production in European organic dairy farms. Livest. Sci. 145:63-72.

Lago, A., S. M. Godden, and P. L. Ruegg. 2014. Treat or not treat? Etiology-based treatment decisions for clinical mastitis. Proc. NMC Annual Meeting. General Session 1: Analytical Approaches to Managing Mastitis, Fort Worth, Texas. National Mastitis Council, Madison, WI.

Lees, N. M., and J. J. Lievaart. 2013. Expert opinion on ranking risk factors for subclinical mastitis using a modified Delphi technique. N. Z. Vet. J. 61:168-173.

Menéndez González, S., A. Steiner, B. Gassner, and G. Regula. 2010. Antimicrobial use in Swiss dairy farms: Quantification and evaluation of data quality. Prev. Vet. Med. 95:50-63.

Mitchell, J. M., M. W. Griffiths, S. A. McEwen, W. B. McNab, and A. J. Yee. 1998. Antimicrobial drug residues in milk and meat: causes, concerns, prevalence, regulations, tests, and test performance. J. Food Prot. 61:742-756.

Noordhuizen, J. P. T. M. 2001. Application of Quantitative Methods in Veterinary Epidemiology. Enfield Publishing and Distribution Co., Enfield, NH.

Piepers, S., K. Peeters, G. Opsomer, H. W. Barkema, K. Frankena, and S. De Vliegher. 2011. Pathogen group specific risk factors at herd, heifer and quarter levels for intramammary infections in early lactating dairy heifers. Prev. Vet. Med. 99:91-101.

Pol, M., and P. L. Ruegg. 2007. Treatment practices and quantification of antimicrobial drug usage in conventional and organic dairy farms in Wisconsin. J. Dairy Sci. 90:249-261. 
Richert, R. M., K. M. Cicconi, M. J. Gamroth, Y. H. Schukken, K. E. Stiglbauer, and P. L. Ruegg. 2013. Risk factors for clinical mastitis, ketosis, and pneumonia in dairy cattle on organic and small conventional farms in the United States. J. Dairy Sci. 96:4269-4285.

Sampimon, O. C., R. Riekerink, and T. Lam. 2008. Prevalence of subclinical mastitis pathogens and adoption of udder health management practices on Dutch dairy farms: Preliminary results. Pages 39-46 in Mastitis Control: From Science to Practice, The Hague, the Netherlands.

Scherpenzeel, C. G. M., I. E. M. den Uijl, G. van Schaik, R. Riekerink, and T. Lam. 2014. Evaluation of the use of dry cow antibiotics in low somatic count cows. J. Dairy Sci. 97:3606-3614.
Stevens, M., S. Piepers, K. Supre, J. Dewulf, and S. De Vliegher. 2016. Quantification of the antimicrobial consumption in adult cattle on dairy herds in Flanders, Belgium, and the association with udder health, milk quality and production performances. J. Dairy Sci. 99:2118-2130. http://dx.doi.org/10.3168/jds.2015-10199.

Werner, C., A. Sobiraj, and A. Sundrum. 2010. Efficacy of homeopathic and antibiotic treatment strategies in cases of mild and moderate bovine clinical mastitis. J. Dairy Res. 77:460-467.

Williamson, J. H., and S. J. Lacy-Hulbert. 2014. Lack of efficacy of homeopathic therapy against post-calving clinical mastitis in dairy herds in the Waikato region of New Zealand. N. Z. Vet. J. 62:8-14. 